\title{
Irving I. Gottesman's Collaboration in Psychiatric Genetics Research in Denmark
}

\author{
Kaare Christensen ${ }^{1}$ and Aksel Bertelsen ${ }^{2}$ \\ ${ }^{1}$ The Danish Twin Registry, University of Southern Denmark, Odense, Denmark \\ ${ }^{2}$ Translational Neuropsychiatry Unit, Department of Clinical Medicine, University of Aarhus, Risskov, Denmark
}

Irving I. Gottesman played an important role for psychiatric genetic research in Denmark through more than 40 years of collaboration with Danish scientists, resulting in important twin and family studies based upon the unique national registers available in Denmark.

In 1972, Irving spent a year as visiting professor in Denmark, after he had completed the Maudsley Twin Study of Schizophrenia together with James Shields. He was fascinated by the register linkage possibilities in Denmark and interested in the Danish twin study of schizophrenia by Margit Fischer at the Psychiatric Hospital in Aarhus, Risskov, and he was on the assessment committee for her dissertation defense in Aarhus.

On this occasion, Irving met Aksel Bertelsen, who was conducting a population-based twin study of manicdepressive disorder. Irving kindly gave useful advice and arranged for an important consultation with James Shields in the 'Genetic Hut' at the Maudsley Hospital. Later, he encouraged the presentation of the results at a twin congress in Washington and at his institute in Minneapolis. Over the following years, their relationship developed into a lifelong friendship and a collaboration into genetic research was formed, resulting in a series of publications.

\section{Confirming Unexpressed Genotypes in Discordant Twins in Fischer's Twin Study of Schizophrenia}

In the mid-1980s, after the untimely death of Margit Fisher in 1983, Irving and Aksel Bertelsen conducted a register study of the morbidity risk in the offspring of Margit Fischer's discordant twins. She had done this for the MZ twins only, because the $\mathrm{DZ}$ twins were considered to be too young at the time of her study. The inclusion of DZ twins now, 20 years later, made it possible to demonstrate a significant difference in the risks in the offspring of $\mathrm{MZ}$ and $\mathrm{DZ}$ twins discordant for schizophrenia. The risk of schizophrenia and schizophrenia-like disorders in the offspring of the schizophrenic and the non-schizophrenic MZ twins were of a similar magnitude, namely $16.8 \%$ and $17.4 \%$ - the same risk as in the offspring of the schizophrenic DZ twins of $17.4 \%$, and about the same as usually found in children with one schizophrenic parent. The risk in the offspring of the non-schizophrenic DZ twins was only $2.1 \%$, like in nephews and nieces. This confirmed that unexpressed genotypes are transmitted to the offspring and also that schizophrenia phenocopies (non-genetic phenotypes that imitate or copy schizophrenia) do not occur to any substantial degree, which is encouraging for molecular research. The study was published in the Archives of General Psychiatry (Gottesman \& Bertelsen, 1989a), and for their paper Gottesman and Bertelsen, together with the late Margit Fischer, received the Schneider Award from Bonn University, which was given to non-Germans for the first time. The manic-depressive discordant twin study showed similar results for the offspring of discordant unipolar $\mathrm{MZ}$ and $\mathrm{DZ}$ pairs, whereas bipolar MZ pairs showed so high a concordance that the sample size provided little statistical power.

\section{'Dual Mating' Studies of Risks in Offspring of Parents Who Had Both Been Psychiatric Inpatients}

From about 1980, Irving had initiated a dual mating study with Margit Fischer, based upon information in the Central Psychiatric Register. Following the death of Fischer, Irving invited Bertelsen to continue her part of the study. The study included 139 parent couples with a total of 378

RECEIVED 10 January 2018; ACCEPTED 15 January 2018

ADDRESS FOR CORRESPONDENCE: Kaare Christensen, The Danish Twin Registry, University of Southern Denmark, J.B. Winsloews Vej 9B, 5000 Odense C, Denmark. E-mail: kchristensen@health.sdu.dk 
offspring. The many parent combinations of different diagnoses had too small numbers of children for statistical analyses. About half of the 378 offspring were healthy, with no admissions or treatment. For the few parent couples, both with schizophrenia or both with manic-depressive disorder, the risks in the offspring of the same disorders as their parents were about 50\% (Gottesman \& Bertelsen, 1989b).

In the early 2000s, Preben Bo Mortensen, the head of the Aarhus University Center for Register Research, invited Irving and Bertelsen to do a nation-wide register study of dual mating. Based upon a population cohort of 2.7 million persons, they obtained risks of schizophrenia in offspring of parent couples of two, one, or no parents with schizophrenia, and risks of bipolar affective disorder in the offspring of couples with two, one, or no parents with bipolar disorder. The risks were calculated as cumulative incidences up to age 52 years and converted to probabilities comparable to the rates in the literature to which they were quite similar (Gottesman et al., 2010).

\section{The Research Collaboration Began and Ended With Twins}

The last collaboration with Irving was a revised and elaborated edition of a new Danish twin study of schizophrenia by Ulla Kläning for her PhD. Irving encouraged the publication of the study and provided an update of the literature and the discussion part, with Susan Trumbetta, a previous student and collaborator of Irving, doing the statistical analysis (Kläning et al., 2016).

Over the years, Irving visited Aarhus almost every summer to work with Bertelsen, who also paid visits to Irving in Charlottesville and Minneapolis. Their friendship and contact continued until Gottesman's sudden death on the June
29, 2016. For Bertelsen, Gottesman was a mentor and a dear, generous and considerate friend. They had many interests in common, using their spare time from the working sessions to pay visits to art museums and exhibitions, art performances and beautiful places. Gottesman's wit and dry humor were very enjoyable and so was his mildly ironical view on people and situations. At a visit to the wilderness of a Danish national park in Western Jutland, Irving dryly remarked that 'you really have to love nature very much not to feel miserable here'. After his last visit to Aarhus in 2006, Gottesman continued to stay in contact with his Danish friends through emails in which he kept them up to date on interesting new articles, usually accompanied by short insightful comments.

\section{References}

Gottesman, I. I., \& Bertelsen, A. (1989a). Confirming unexpressed genotypes in schizophrenia. Risks in offspring of Fischer's Danish identical and fraternal twins. Archives of General Psychiatry, 46, 867-872.

Gottesman, I. I., \& Bertelsen, A. (1989b). Dual mating studies in psychiatry - Offspring of inpatients with examples from reactive (psychogenic) psychoses. International Review of Psychiatry, 1, 287-296.

Gottesman, I. I., Laursen, T. M., Bertelsen, A., \& Mortensen, P. B. (2010). Severe mental disorders in offspring with 2 psychiatrically ill parents. Archives of General Psychiatry, 67, 252-257.

Kläning, U., Trumbetta, S. L., Gottesman, I. I., Skytthe, A., Kyvik, K. O., \& Bertelsen, A. (2016). A Danish twin study of schizophrenia liability: Investigation from interviewed twins for genetic links to affective psychoses and for cross-cohort comparisons. Behavior Genetics, 46, 193204. 